\title{
A Simple Multiproduct Multimachine Production Planning Model
}

\author{
Boudjelal Boukaabar $^{1} \&$ Mohamed Kheireddine Dellil ${ }^{1}$ \\ ${ }^{1}$ Faculté des sciences économiques, des sciences commerciales et sciences de gestion, Oran Es-Senia University, \\ Oran, Algeria \\ Correspondence: Boudjelal Boukaabar, Faculté des sciences économiques, des sciences commerciales et sciences \\ de gestion, Oran Es-Senia University, Oran, Algeria. Tel: 213-6-6125-0758. E-mail: b.boudj@hotmail.fr
}

Received: January 2, 2013

Accepted: January 28, 2013

Online Published: February 5, 2013

doi:10.5539/ibr.v6n3p192

URL: http://dx.doi.org/10.5539/ibr.v6n3p192

\begin{abstract}
Business models of production management and planning have known an important development. Whether it is M.R.P, Kamban or JAT, these planning methods of production require the mastery of the information system. Unfortunately, seldom does such system exist in small and medium size businesses. Sometimes, sophisticated systems based on these methods of production planning were acquired by companies that could afford them only to discover in the end that these systems were not usable because they require a certain level of formation and competence of the human factor, which level is nonexistent in small and medium enterprises and even in larger enterprises in developing countries. Could a more flexible planning system not requiring the existence of an information system too rigid and which can be run by less experienced agents be developed? This article answers this question in the affirmative.
\end{abstract}

Keywords: multi-machine, multi-product, multi-period, material requirement planning, production planning, minimizing production cost, simplex

\section{Introduction}

Production is the main activity of most of the enterprises, it is essential to master its mechanics. Several models and methods have been developed in order to achieve optimal management of production. Among these models and methods we can mention Material Requirement Planning (MRP) (Albert Courtois, 1992) KANBAN (Keysuki Arai \& Kenichi Sekine, 2006), the Just In Time (JIT) (Shiugo Shigeo, 1988) and finally the so-called OPT (James R Evans, 1993).

The implementation of such technologies requires efficient information system which often proves costly to implement and heavy to maintain functioning. This is due to the important flow of information required by such systems. In a small or medium business environment, it is often impossible to implement such systems for the following reasons:

- The cost of acquisition and continued operation of the hardware and software necessary for the proper monitoring of the production process.

- The lack of training of staff charged with feeding data into the information system and operating the appropriate hardware.

Faced with such constraints, one might ask if there would be a system easier to implement and maintain. We propose to formalize such a model that requires very little information, and is easily implementable in small to midsized businesses.

\section{The Model}

We consider the case of an enterprise which makes several different products. Such enterprise has a series of machines, each of which is capable of performing all the operations required to produce one unit of one of these products. In other words, any one item is the result of a single machine. The machines can make any product.

In this enterprise, there is an inventory of raw material from which all the machines draw. Just as there is a single inventory for each of the final products. These machines can be different and therefore they will be characterized by different production capacities and manufacturing costs.

To allow for the possibility of maintenance shutdowns, production capacity of a given machine may vary from one 
period to another.

The enterprise must meet the demand for each product, it is not allowed to enter into shortage periods.

We assume that the demand is known for it is either:

- demand on the enterprise customers orders books,

- anticipated demand.

In order to meet the demand of the different periods that make up the planning horizon, the enterprise must determine which product to make, which machine to use, when and how much to produce. Most often this planning horizon is the year and the period is the month (or week). In parallel with the goal of satisfying the demand of the customers, the company would strive to minimize the overall cost. The overall cost comprises two costs classes: the production cost and the holding cost.

The first constraint imposed on the enterprise is the production capacity. We cannot produce more than permitted by the machines. This constraint can be easily circumvented by drawing, the difference between the total capacity of the machines and the demand, from the inventories. These would have been accumulated during the periods when the capacity exceeded the demand. The constitution of inventories should not lead the enterprise to incur unnecessary costs. Indeed, we must take into consideration the costs associated with such a transfer of production from one period to another because production costs vary from one period to another: the price of farm products such as tomato decreases significantly in the summer thus leading to a lower cost of production of tomato paste. Thus, the enterprise might be tempted to produce the maximum of the tomato paste in the tomato season to take advantage of the tomato price differential. Unfortunately, such a policy stumbles on the question of storage costs.

A product not sold implies extra expenses: interests paid to the bank for advancing funds for the purchase of raw materials, lack of income due to loss and or spoil, amortization of the investment required for the storage (such as the purchase or rental of a storage area or specific equipment), inventory holding cost when it requires appropriate conditions (e.g. the use of low temperatures), and finally the costs of caretaking and inventory control.

In such a situation, the gains made by lower production costs should not be offset by excessive storage/holding costs. The whole problem is to choose a production schedule that benefit to the maximum from the raw material price cuts and maintain the overall storage cost to a minimum level. In other words, the sum of production costs and storage costs should be at its minimum. This is the goal to achieve.

\section{Notation}

$\mathrm{T}$ : Number of periods in the planning horizon.

$\mathrm{t}$ : Index of period in the planning horizon; $\mathrm{t}=1,2, \ldots, \mathrm{T}$.

M: Number of machines.

i: Index of a machine; $\mathrm{i}=1,2, \ldots, \mathrm{M}$.

$\mathrm{N}$ : Number different products.

$\mathrm{j}$ : Index of a product; $\mathrm{j}=1,2, \ldots, \mathrm{N}$.

$\mathrm{X}_{\mathrm{ijt}}$ : Number of units of product $\mathrm{j}$ produced on machine $\mathrm{i}$ in period $\mathrm{t}$.

$\mathrm{P}_{\mathrm{it}}$ : Production capacity of the ith machine in period $\mathrm{t}$.

$a_{i j}$ : Capacity units needed to process one unit of product $j$ on machine $i$.

$\mathrm{I}_{\mathrm{jt}}$ : Inventory of product $\mathrm{j}$ at the end of period $\mathrm{t}$.

$\mathrm{D}_{\mathrm{jt}}$ : Demand for product $\mathrm{j}$ in period $\mathrm{t}$.

$\mathrm{C}_{\mathrm{ij}}$ : Cost of producing one unit of product $\mathrm{j}$ on machine $\mathrm{i}$ in period $\mathrm{t}$.

$\mathrm{h}_{\mathrm{jt}}$ : Holding cost for product $\mathrm{j}$ in period $\mathrm{t}$.

\section{Cost Evaluation}

\subsection{The Production Cost}

Let's consider some machine $\mathrm{i}$ in a given period $\mathrm{t}$. For a given product $\mathrm{j}, \mathrm{X}_{\mathrm{ijt}}$ units are produced and the cost of producing each unit is $\mathrm{C}_{\mathrm{ijt} \text {. }}$ The total cost for this machine at this time period $t$ and for this product $\mathrm{j}$ is $\mathrm{C}_{\mathrm{ijt}} \mathrm{X}_{\mathrm{ijt}}$.

The cost incurred on that particular machine $\mathrm{i}$ for that particular time period $\mathrm{t}$ is for all the products: 


$$
\sum_{j=1}^{N} X_{i j t} C_{i j t}
$$

Equation (1) assumes that the cost of production is linear. This means that regardless of the level of production for a given machine $i$ at a given time period $t$, the $\operatorname{cost} C_{i j t}$ does not vary with the level of output $X_{i j t}$.

The production cost for any given period $t$ is simply the sum over all machines $i$ of equation (1). That is:

$$
\sum_{i=1}^{M} \sum_{j=1}^{N} X_{i j t} C_{i j t}
$$

The total production cost for the planning horizon is obtained by summing up (2) over all periods $\mathrm{t}$ :

$$
\sum_{t=1}^{T} \sum_{i=1}^{M} \sum_{j=1}^{N} X_{i j t} C_{i j t}
$$

\subsection{The Holding Cost}

If for a given product $\mathrm{j}$ the inventory at the end of period $\mathrm{t}$ is $\mathrm{I}_{\mathrm{jt}}$ and if the associated holding cost for product $\mathrm{j}$ in period $t$ is $h_{j}$, then the inventory cost for that single product and for that time period is:

$$
\mathrm{h}_{\mathrm{jt}} \mathrm{I}_{\mathrm{jt}}
$$

Thus, for all the products the holding cost for a given period $t$ is seen to be:

$$
\sum_{j=1}^{N} h_{j t} I_{j t}
$$

Last, the total holding cost for the entire planning horizon is obtained by summing equation (5) over all periods t:

$$
\sum_{t=1}^{T} \sum_{j=1}^{N} h_{j t} I_{j t}
$$

It should be noted that equations (4) to (6) provide that the cost of storage may vary from one period to another. An example of such a cost varying with time is given by products that require to be kept in the cold. Under such conditions, the storage costs incurred in winter are certainly lower than those undergone in the summer.

\subsection{The Total Cost}

The total cost over the planning horizon is the sum of the total production cost (3) and the total holding cost (6).

$$
\sum_{t=1}^{T} \sum_{i=1}^{M} \sum_{j=1}^{N} X_{i j t} C_{i j t}+\sum_{t=1}^{T} \sum_{j=1}^{N} h_{j t} I_{j t}
$$

The goal of good management is to keep the total cost as expressed by equation (7) to its minimum level. Also we can mathematically formulate this objective as follows:

$$
\min \mathrm{z}=\sum_{t=1}^{T} \sum_{i=1}^{M} \sum_{j=1}^{N} X_{i j t} C_{i j t}+\sum_{t=1}^{T} \sum_{j=1}^{N} h_{j t} I_{j t}
$$

\section{The Constraints}

The production process undergoes several constraints. There are:

- Budgetary constraints: the enterprise cannot exceed a certain level of investment in stocks of raw materials and finished products.

- Technical constraints: failure due to spare parts, power failure, etc..

- Technological constraints: at a given time $t$, a given machine i cannot produce more than its capacity.

- Logical constraints: the production and inventories cannot have negative values.

The proposed model takes into account the last two types of constraints.

The model we aim at consists in minimizing the total cost of production during a planning horizon of $\mathrm{T}$ periods. The demand will be met by deciding the production levels as well as the levels of the inventories at the end of each period. If the production cost is higher than the holding cost, the requested quantity is satisfied from the inventories if there are any and if necessary, planned quantities are launched for production. On the other hand, if the cost of 
production is significantly lower than the holding cost, it would be absurd not to meet the demand from planned quantities to be produced.

\subsection{The Capacities Constraints}

If producing one unit of product $j$ on machine $i$ consumes $a_{i j}$ units of the capacity of that machine $i$, then for a given level of production $\mathrm{X}_{\mathrm{ijt}}$ the number of capacity units consumed is:

$$
\mathrm{a}_{\mathrm{ijj}} \mathrm{X}_{\mathrm{ijt}}
$$

Hence all the products produced on machine i will consume

$$
\sum_{j=1}^{N} a_{i j} X_{i j t}
$$

Since the machine has a capacity that we cannot go beyond, the capacity constraint is seen to be:

$$
\sum_{j=1}^{N} a_{i j} X_{i j t} \leq P_{i t} \quad \text { for each } \mathrm{i}=1,2, \ldots, \mathrm{M} \text { and each } \mathrm{t}=1,2, \ldots, \mathrm{T}
$$

\subsection{The Balance Constraints}

The balance constraint simply states that for each product $j$, the inventory at the end of period $t$ is equal to the inventory at the end of the prior period ( $\mathrm{t}-1$ ) augmented by whatever was produced on all the machines during the period $t$ and reduced by the demand satisfied during that same period $t$.

$$
I_{j t}=I_{j(t-1)}+\sum_{i=1}^{M} X_{i j t}-D_{j t} \quad \text { for each } \mathrm{j}=1,2, \ldots, \mathrm{N} \text { and each } \mathrm{t}=1,2, \ldots, \mathrm{T}
$$

\subsection{The Non Negativity Constraints}

Since neither the production levels $\mathrm{X}_{\mathrm{ijt}}$ nor the inventory levels $\mathrm{I}_{\mathrm{jt}}$ can be negative, we shall add the following constraints:

$$
X_{i j t} \geq 0 ; I_{j t} \geq 0 \text { for each } i=1,2, \ldots, M ; \text { each } j=1,2, \ldots, N \text { and each } t=1,2, \ldots, T
$$

We shall assume that the starting inventories are null for each product $\mathrm{j}$ :

$$
\mathrm{I}_{\mathrm{j} 0}=0 \quad \text { for each } \mathrm{j}=1,2, \ldots, \mathrm{N}
$$

The final set of constraints (14) has been added on the initial inventory at the beginning of the first period. This is necessary because the balance constraint refers to the inventory of the preceding period. In case this inventory is not null, a simple solution would be to subtract the initial inventory from demands of the first periods constituting the planning horizon but without resulting in negative demands.

\section{The Model}

let's put together the objective (8) and the set of constraints (11) to (14).

$$
\min \mathrm{z}=\sum_{t=1}^{T} \sum_{i=1}^{M} \sum_{j=1}^{N} X_{i j t} C_{i j t}+\sum_{t=1}^{T} \sum_{j=1}^{N} h_{j t} I_{j t}
$$

Subject to:

$$
\begin{aligned}
& \sum_{j=1}^{N} a_{i j} X_{i j t} \leq P_{i t} \text { for each } \mathrm{i}=1,2, \ldots, \mathrm{M} \text { and each } \mathrm{t}=1,2, . ., \mathrm{T} \\
& I_{j t}=I_{j(t-1)}+\sum_{i=1}^{M} X_{i j t}-D_{j t} \text { for each } \mathrm{j}=1,2, \ldots, \mathrm{N} \text { and each } \mathrm{t}=1,2, \ldots, \mathrm{T} \\
& \mathrm{X}_{\mathrm{ijt}} \geq 0 ; \mathrm{I}_{\mathrm{jt}} \geq 0 \text { for each } \mathrm{i}=1,2, \ldots, \mathrm{M} ; \text { each } \mathrm{j}=1,2, \ldots, \mathrm{N} \text { and each } \mathrm{t}=1,2, \ldots, \mathrm{T} \\
& \mathrm{I}_{\mathrm{j} 0}=0 \text { for each } \mathrm{j}=1,2, \ldots, \mathrm{N} \\
& 6.1 \text { Number of } \text { Variables }
\end{aligned}
$$

\subsection{Number of Variables}

The variables to be determined are the $X_{\mathrm{ijt}}$ the production levels on each machine for each period and for each product on one hand and the $\mathrm{I}_{\mathrm{jt}}$ the inventory levels for each product at the end of each period on the other. Therefore there are $\mathrm{M}^{*} \mathrm{~T}^{*} \mathrm{~N}$ variables $\mathrm{X}_{\mathrm{ijt}}$ and $\mathrm{T}^{*} \mathrm{~N}$ variables $\mathrm{I}_{\mathrm{jt}}$. That is $\mathrm{T}^{*} \mathrm{~N}^{*}(\mathrm{M}+1)$ decision variables. 


\subsection{Number of Inequalities}

For each machine $\mathrm{i}$ and for each period $\mathrm{t}$, there is one inequality of the type (11). It follows that the total number of such inequalities is equal to $\mathrm{M} * \mathrm{~T}$. Moreover, for each period $t$ and for each product $\mathrm{j}$ we have an equation of the type (12). There is therefore $T^{*} \mathrm{~N}$ equations. The total number of constraints (equation or inequality) is equal to $\mathrm{T}$ $*(\mathrm{M}+\mathrm{N})$.

\section{Solution}

The set of equations and inequations in (8) and (11) to (14) form a linear program which can be easily solved using the simplex method.

\section{Conclusion}

Although the model presented is rather limited, it can easily be developed in the following cases:

- model with budget constraint;

- model with limited space or storage volume.

The model requires very little information: Assessing the demands for the different periods of the planning horizon, the production and holding costs and the capacities of the machines. This is very little information compared to the requirements of the MRP based models for example.

Among the methods for solving linear programming problems, the simplex method allows easy handling. This method is known, recognized, often used, easy to use and inexpensive. The level of the informational complexity is within reach of small businesses.

In addition, the computer software implementing the simplex method for solving such a problem can be run on any personal computer with minimum time. Several simplex-based software are available and affordable. Some are even free-share.

The proposed model can be enhanced in response to the changing information needs of the enterprise and its constraints. Thus, an additional inequality could change the model for the management of budgetary constraints or space constraints or volume required for storage of the products.

This model is therefore a simple and inexpensive alternative compared to other planning methods such as MRP method.

\section{References}

Arai, K., \& Sekine, K. (2006). Kaizen for Quick Changeover: Going Beyond SMED. Productivity Press.

Bonine, J., \& Kiyoshi, S. (1987). Produire juste à temps. Editions Masson, France.

Courtois, A. (1992). Gestion de production. Editions d'organisation, France.

Evans, J. R. (1993). Applied Productions and operations Management. West Publishing.

Johnson, L. A., \& Montgomery, C. (1974). Operations Research in Production Planning, Scheduling and Inventory Control. John Wiley.

Shigeo, S. (1988). Non Stock Production: The Shingo System of Continuous Improvement. Production Press. 